\title{
Quantitative Tomography Simulations and Reconstruction Algorithms
}

\author{
H. E. Martz, Jr., M. B. Aufderheide, III, D. Goodman, A. \\ Schach von Wittenau, C. Logan, J. Hall, J. Jackson, D.
Slone
}

\section{November 1, 2000}

Lawrence

Livermore

National

Laboratory

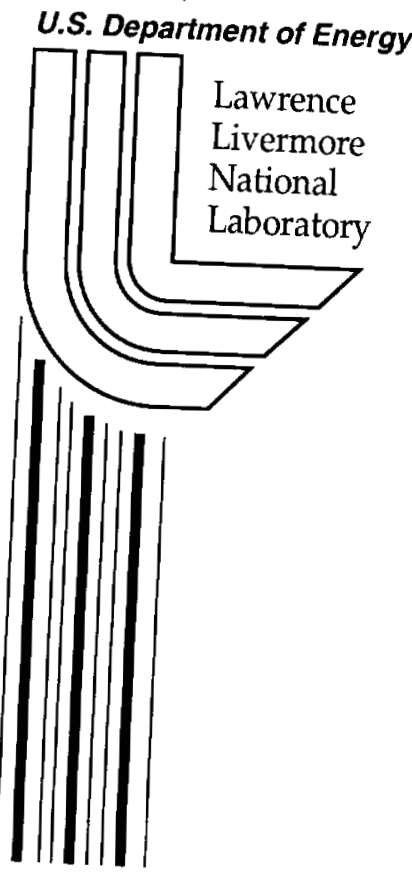




\section{DISCLAIMER}

This document was prepared as an account of work sponsored by an agency of the United States Government. Neither the United States Government nor the University of California nor any of their employees, makes any warranty, express or implied, or assumes any legal liability or responsibility for the accuracy, completeness, or usefulness of any information, apparatus, product, or process disclosed, or represents that its use would not infringe privately owned rights. Reference herein to any specific commercial product, process, or service by trade name, trademark, manufacturer, or otherwise, does not necessarily constitute or imply its endorsement, recommendation, or favoring by the United States Government or the University of California. The views and opinions of authors expressed herein do not necessarily state or reflect those of the United States Government or the University of California, and shall not be used for advertising or product endorsement purposes.

This work was performed under the auspices of the U. S. Department of Energy by the University of California, Lawrence Livermore National Laboratory under Contract No. W-7405-Eng-48.

This report has been reproduced directly from the best available copy.

Available electronically at http://www.doc.gov/bridge

Available for a processing fee to U.S. Department of Energy

And its contractors in paper from

U.S. Department of Energy

Office of Scientific and Technical Information

$$
\text { P.O. Box } 62
$$

Oak Ridge, TN 37831-0062

Telephone: (865) 576-8401

Facsimile: (865) 576-5728

E-mail: reports@adonis.osti.gov

Available for the sale to the public from

U.S. Department of Commerce

National Technical Information Service

5285 Port Royal Road

Springfield, VA 22161

Telephone: (800) 553-6847

Facsimile: (703) 605-6900

E-mail: orders@ntis.fedworld.gov

Online ordering: http://www.ntis.gov/ordering.htm

\section{OR}

Lawrence Livermore National Laboratory

Technical Information Department's Digital Library

http://www.llnl.gov/tid/Library.html 


\section{Quantitative Tomography Simulations and Reconstruction Algorithms ${ }^{\dagger}$}

H. E. Martz, Ir., M. B. Aufderheide, III, D. Goodman, A. Schach von Wittenau,

C. Logan, J. Hall, J. Jackson and Dale Slone

99-ERD-015

$X$-ray, neutron and proton transmission radiography and computed tomography (CT) are important diagnostic tools that are at the heart of LLNL's effort to meet the goals of the DOE's Advanced Radiography Campaign. This campaign seeks to improve radiographic simulation and analysis so that radiography can be a useful quantitative diagnostic tool for stockpile stewardship.

Current radiographic accuracy does not allow satisfactory separation of experimental effects from the true features of an object's tomographically reconstructed image. This can lead to difficult and sometimes incorrect interpretation of the results. By improving our ability to simulate the whole radiographic and CT system, it will be possible to examine the contribution of system components to various experimental effects, with the goal of removing or reducing them. In this project, we are merging this simulation capability with a maximum-likelihood (constrained-conjugategradient-CCG) reconstruction technique yielding a physics-based, forward-model image-reconstruction code. In addition, we seek to improve the accuracy of computed tomography from transmission radiographs by studying what physics is needed in the forward model.

During FY 2000, an improved version of the LLNL ray-tracing code called HADES has been coupled with a recently developed LLNL CT algorithm known as CCG. The problem of image reconstruction is expressed as a large matrix equation relating a model for the object being reconstructed to its projections (radiographs). Using a constrained-conjugate-gradient search algorithm, a maximum likelihood solution is sought. This search continues until the difference between the input measured radiographs or projections and the simulated or calculated projections is satisfactorily small.

We developed a 2D HADES-CCG CT code that uses full ray-tracing simulations from HADES as the projector. Often an object has axial symmetry and it is desirable to reconstruct into a $2 \mathrm{D} \mathrm{r}-\mathrm{z}$ mesh with a limited number of projections. The physics (e.g., scattering and detector response) required in the HADES code is determined from Monte Carlo simulations. The current version of HADES-CCG reconstructs into a volume-density mesh made of one material and assumes a monochromatic source.

Both 10-MeV neutrons and 9-MV x-rays were used to image a British Test Object (BTO). This object consists of a set of nested $\mathrm{C}, \mathrm{W}$ and polyethylene shells and is used for tomographic algorithm verification. The neutron and $x$-ray radiographs (Figure left side) of the BTO show some of the joint and different material details. However, it is difficult to use the radiographic projection data to obtain detailed quantitative measurements of the joint thickness, material boundaries, etc. To extract more details from the BTO radiographs, a single radiographic projection was used to obtain a $2 \mathrm{D} \mathrm{CT}$ cross section of the BTO (Figure, right side). These cross sections were obtained using the current HADES-CCG code. Comparing the $x$-ray to the neutron $C T$ reconstructions

\footnotetext{
${ }^{+}$This work was performed under the auspices of the U.S. Department of Energy by The University of California Lawrence Livermore National Laboratory under contract No. W-7405-ENG-48.
} 
on the right of the Figure, it is apparent that spatial resolution is superior in the $\mathrm{x}$-ray image. This is expected and is largely due to source unsharpness.

Our current implementation of HADES-CCG has shown interesting potential, but more work is needed to make a fully viable reconstruction code. In FY 2001 we will study the treatment of multiple materials and polychromatic sources in a reconstruction. We will expand the HADES-CCG code to include 3D reconstructions in FY 2001, broadening its applicability.
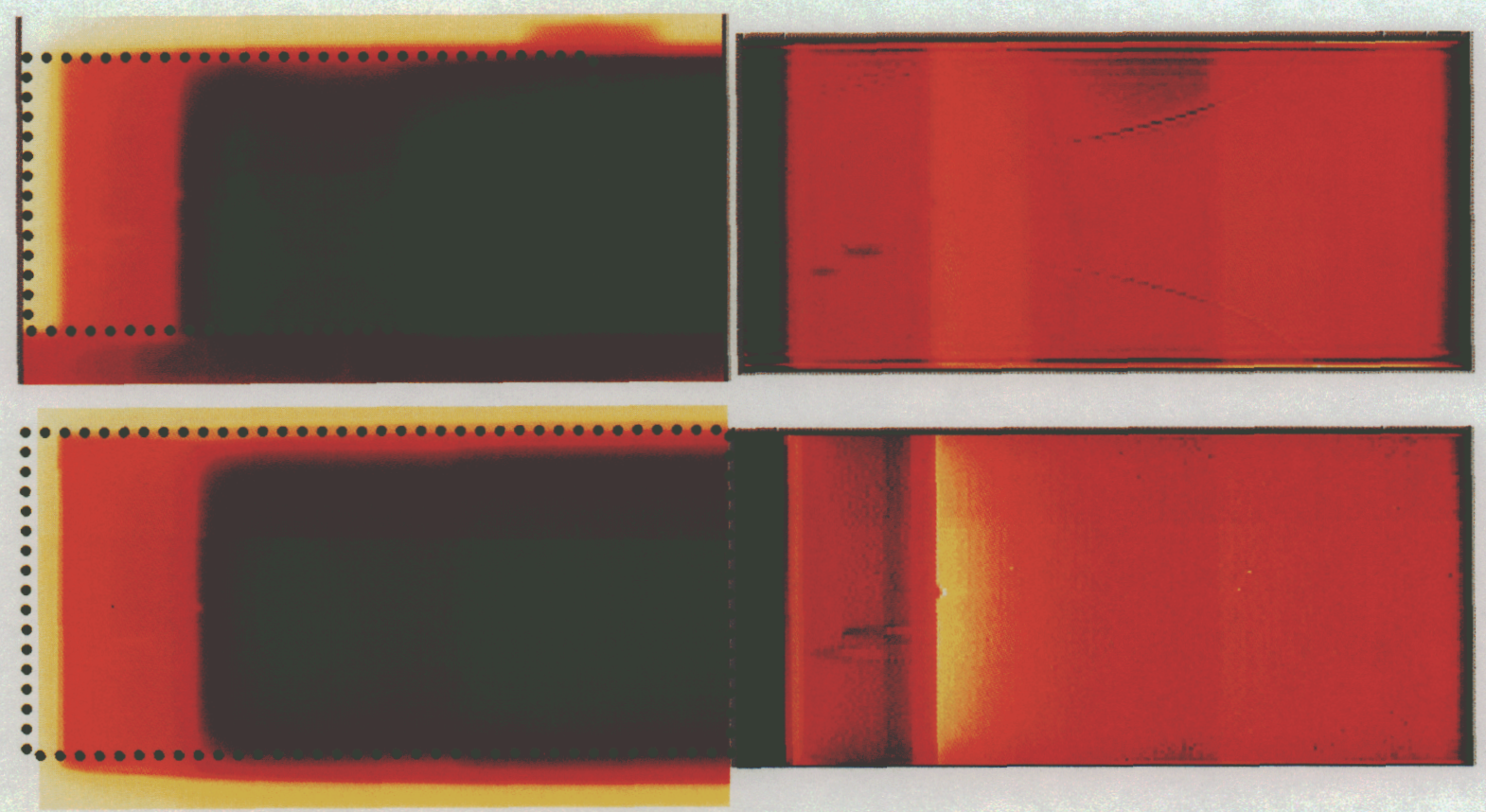

Top: Left: $10-\mathrm{MeV}$ neutron radiograph of the BTO. Right: 2D CT reconstruction of the BTO using the single radiograph shown to the left. Bottom: Left: 9-MV x-ray radiograph of the BTO. Right: 2D CT reconstruction of the BTO using the single radiograph shown to the left. The dotted box highlights the portion of the radiograph used to obtain the 2D crosssectional $\mathrm{CT}$ data in each case. Both CT images were reconstructed into the same voxel size of $0.5 \mathrm{~mm} \times 0.5 \mathrm{~mm}$. 